\title{
Response to Mepolizumab Treatment in Patients with Severe Eosinophilic Asthma and Atopic Phenotypes
}

\author{
Charlene M Prazma' \\ Marco Idzko 2,3 \\ Jo Anne Douglass ${ }^{4}$ \\ Arnaud Bourdin iD ${ }^{5,6}$ \\ Stephen Mallett ${ }^{7}$ \\ Frank C Albers ${ }^{8}$ \\ Steven W Yancey'
}

'Respiratory Therapeutic Area, GSK, Research Triangle Park, NC, USA; ${ }^{2}$ Division of Pneumology, Medical University of Vienna, Vienna, Austria; ${ }^{3}$ Department of Pneumology, University Hospital Freiburg, Freiburg, Germany; ${ }^{4}$ The Royal Melbourne Hospital and University of Melbourne, Melbourne, VIC, Australia;

${ }^{5}$ Departement de Pneumologie et Addictologie, Hôpital Arnaud de Villeneuve, CHU Montpellier Montpellier, France; ${ }^{6}$ PhyMedExp, University of Montpellier, Montpellier, France; ${ }^{7}$ Clinical Statistics, GSK, Uxbridge, Middlesex, UK;

${ }^{8}$ Respiratory Medical Franchise, GSK, Research Triangle Park, NC, USA

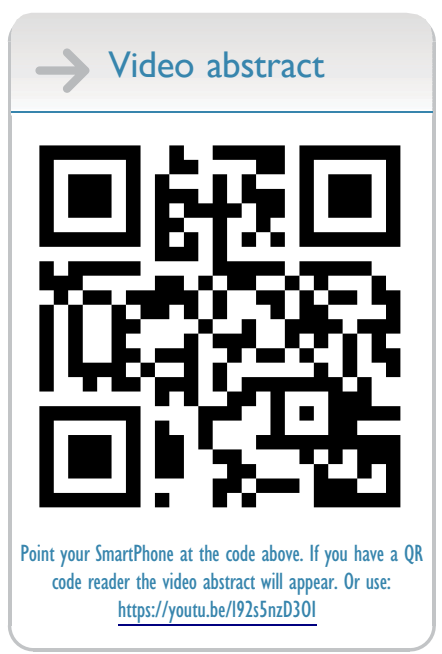

Correspondence: Charlene M Prazma Respiratory Therapeutic Area, GSK, 5 Moore Drive, PO Box 13398, Research Triangle Park, NC, 27709, USA $\mathrm{Tel}+19194839013$

Email charlene.m.prazma@gsk.com
Purpose: Improved understanding of characteristics that may influence treatment response across phenotypes may help guide treatment decisions.

Patients and Methods: This was a post hoc analysis of MENSA, a multicenter, randomized, double-blind, placebo-controlled trial (NCT01691521). Patients aged $\geq 12$ years with severe eosinophilic asthma received mepolizumab $(75 \mathrm{mg}$ intravenously or $100 \mathrm{mg}$ subcutaneously) or placebo, plus standard of care, every 4 weeks for 32 weeks. Outcomes assessed were the annualized rate of clinically significant exacerbations and change from baseline in Asthma Control Questionnaire (ACQ)-5 score. Subgroup analyses were performed by baseline blood eosinophil count $(<150, \geq 150-300, \geq 300$ cells $/ \mu \mathrm{L}$ ) within atopic subgroups (nonatopic [specific immunoglobulin $\mathrm{E}<0.35 \mathrm{kU} / \mathrm{L}$ ], atopic $[\geq 0.35-17.5 \mathrm{kU} / \mathrm{L}$ ], strongly atopic [>17.5 kU/L]), and by house dust mite (HDM) sensitivity.

Results: Of 576 patients analyzed, 272 were non-atopic, 181 were atopic and 94 were strongly atopic; 29 had missing atopy data. In patients with blood eosinophil counts $\geq 300$ cells $/ \mu \mathrm{L}$, mepolizumab versus placebo reduced clinically significant exacerbations by $74 \%$, $43 \%$ and $25 \%$ in the non-atopic, atopic and strongly atopic subgroups. Similar reductions were observed in all atopic subgroups in other blood eosinophil count categories where there were sufficient patient numbers for analysis, except for non-atopic patients with baseline blood eosinophil counts of $<150$ cells $/ \mu \mathrm{L}$. Improvements in ACQ-5 scores of $-0.75,-0.73$ and -0.78 with mepolizumab versus placebo were observed in non-atopic, atopic and strongly atopic patients with blood eosinophil counts $\geq 300$ cells $/ \mu \mathrm{L}$; consistent improvements in ACQ-5 were not observed in patients with blood eosinophil counts $<150$ or $\geq 150-300$ cells $/ \mu \mathrm{L}$. Reductions in clinically significant exacerbations with mepolizumab versus placebo were also observed irrespective of sensitivity to HDMs.

Conclusion: Mepolizumab was associated with a trend for reductions in clinically significant exacerbations and improved asthma control versus placebo in patients with severe eosinophilic asthma, irrespective of atopic status or HDM sensitivity.

Keywords: allergens and epitopes, eosinophils, asthma, asthma treatments, biologics

\section{Introduction}

Severe asthma is a heterogeneous disease comprising different and overlapping phenotypes driven by distinct pathophysiological processes. ${ }^{1}$ These phenotypes are distinguished by clinical characteristics, physiological measures and biomarker expression. ${ }^{2,3}$ Two such phenotypes, severe allergic asthma and severe eosinophilic asthma, are driven by the type 2 immune response. ${ }^{4}$ Severe allergic asthma is characterized by an early age of disease onset, high serum immunoglobulin 
E (IgE), specific allergen sensitization, and eosinophilic inflammation, while patients with severe eosinophilic asthma typically have a later age of onset, eosinophilic inflammation and recurrent exacerbations, although there is overlap in the clinical presentation of these phenotypes. $^{2,3}$

Advances in our understanding of the biological mechanisms underlying severe asthma have provided several disease biomarkers and therapeutic targets. For example, it is established that the airway epithelium is the first line of defense against inhaled allergens and plays a major role in the resulting immune response. ${ }^{5}$ Stimulation of the airway epithelium results in the release of alarmins that leads to the recruitment and activation of innate and adaptive immune cells, and the release of inflammatory mediators such as IgE, interleukin (IL)-4, IL-5 and IL-13. ${ }^{5}$ As a result, several biologic therapies have been developed that target these mediators. For example, omalizumab, a humanized monoclonal anti-IgE antibody has been developed and approved for use as add-on therapy in patients with moderate to severe allergic asthma, ${ }^{6,7}$ and mepolizumab, an anti-IL-5 monoclonal antibody, is indicated for use in patients with severe eosinophilic asthma. $^{8,9}$

Decisions regarding the use of add-on biologic therapy in patients with severe asthma are based on a phenotypic assessment, and can also include an assessment of biomarkers (such as IgE levels, eosinophil counts and FeNO). ${ }^{1,10}$ In some cases, an assessment of sensitization to particular allergens is also considered. ${ }^{1,10}$ Historically, allergen sensitivity has been a hallmark assessment of allergic asthma. However, based on phenotypic and clinical classifications, predictors of patient response to omalizumab are very similar to those predicting a response to mepolizumab, ${ }^{11,12}$ and it has been reported that approximately $30 \%$ of patients eligible for mepolizumab are also eligible for omalizumab. ${ }^{11}$ With the increasing availability of targeted therapies that neutralize different mediators of inflammation, further understanding of patient characteristics that may influence treatment response across phenotypes is needed to inform prescribing choices.

The previously reported MENSA study (GSK ID: MEA115588; NCT01691521) evaluated the efficacy of mepolizumab in patients with severe eosinophilic asthma, and found that the rate of clinically significant exacerbations was significantly reduced and asthma control was improved with mepolizumab compared with placebo. ${ }^{13}$ The objective of this post hoc, subgroup analysis was to compare the effect of mepolizumab across different atopic phenotypes and baseline blood eosinophil count categories in patients from the MENSA study. Subgroup analyses were also performed by sensitivity to particular allergens, including the two common species of house dust mites (HDMs), Dermatophagoides pteronyssinus and Dermatophagoides farinae.

\section{Patients and Methods Study Design}

This was a post hoc, subgroup analysis of MENSA, full details of which have been reported previously. ${ }^{13}$ In brief, MENSA was a multicenter, randomized, placebocontrolled, double-dummy, double-blind, parallel-group trial. Following a 1-6-week run-in period, patients were randomized (1:1:1) to receive mepolizumab $75 \mathrm{mg}$ intravenously (IV), mepolizumab $100 \mathrm{mg}$ subcutaneously (SC) or placebo, in addition to standard of care, every 4 weeks for 32 weeks. The primary study was conducted in accordance with the ethical principles of the Declaration of Helsinki, International Council for Harmonization Good Clinical Practice, and the applicable country-specific regulatory requirements. The local institutional review board or ethics committee at each study center oversaw trial conduct and documentation (see Supplementary Material for further details). All patients provided written informed consent.

\section{Patients}

MENSA enrolled patients $\geq 12$ years of age with severe eosinophilic asthma (blood eosinophil count: $\geq 300$ cells/ $\mu \mathrm{L}$ in the previous year or $\geq 150$ cells $/ \mu \mathrm{L}$ at screening) and a history of $\geq 2$ exacerbations in the year prior to enrolment despite regular treatment with high-dose inhaled corticosteroids (ICS) in the 12 months prior to screening, plus additional controller medication(s) for $\geq 3$ months prior to screening. Patients with biologic use within 130 days or five half-lives of administration at screening were excluded.

\section{Post Hoc Endpoints and Assessments}

The primary outcome for this analysis was the annualized rate of clinically significant exacerbations, defined as a worsening of asthma requiring systemic corticosteroids for $\geq 3$ days and/or emergency room visit and/or hospitalization. The secondary outcome was the change from 
baseline in Asthma Control Questionnaire (ACQ)-5 score at study end.

At baseline, specific IgE titers to D. pteronyssinus (HDM 1), D. farinae (HDM 2), dog dander, cat dander, Alternaria alternata and cockroach were measured. Sensitivity to these allergens was classified into seven categories: class $0(\operatorname{IgE}<0.35 \mathrm{kU} / \mathrm{L})$; class 1 ( $\operatorname{IgE} 0$.$35-0.70 \mathrm{kU} / \mathrm{L})$; class 2 (IgE $0.71-3.50 \mathrm{kU} / \mathrm{L})$; class 3 (IgE 3.51-17.50 kU/L); class $4(\operatorname{IgE} 17.60-50.00 \mathrm{kU} / \mathrm{L})$; class 5 (IgE $51.00-100.00 \mathrm{kU} / \mathrm{L})$; class $6(\operatorname{IgE}>100.00$ $\mathrm{kU} / \mathrm{L}$ ). Post hoc subgroup analyses were performed by baseline blood eosinophil count within atopy strength categories. Patients were categorized as non-atopic (class 0 ), atopic (classes 1, 2 and 3) or strongly atopic (classes 4, 5 and 6). Within these atopic strength categories, patients were further grouped according to baseline blood eosinophil count $(<150$ cells $/ \mu \mathrm{L}, 150-<300$ cells $/ \mu \mathrm{L}$ or $\geq 300$ cells $/ \mu \mathrm{L}$ ).

Additional post hoc subgroup analyses were performed by HDM sensitivity and sensitivity to additional allergens. Based on the baseline IgE measurements, patients were categorized as HDM-sensitive (classes 1-6 to D. pteronyssinus or D. farinae) or HDM non-sensitive (class 0 to $D$. pteronyssinus and $D$. farinae). Within HDM sensitivity categories, patients were further grouped according to their sensitivity to additional allergens (ie, $\geq 1$, $\geq 2$ or $\geq 3$ additional allergens; $A$. alternata, cockroach, cat dander or dog dander).

\section{Statistical Analysis}

Patients who received $\geq 1$ dose of study drug were included in the analysis and formed the modified intent-to-treat (mITT) population.

Due to similar bioequivalence and efficacy, ${ }^{13}$ mepolizumab doses (75 mg IV/100 mg SC) were combined in this analysis. Analysis of the number of exacerbations was performed using separate negative binomial models for each subgroup, with covariates of treatment group, baseline maintenance oral corticosteroid (OCS) therapy, region, exacerbations in the year prior to the study and baseline percent predicted forced expiratory volume in $1 \mathrm{~s}\left(\mathrm{FEV}_{1}\right)$. Analysis of change from baseline in ACQ-5 score was performed using mixed model repeated measures for each subgroup, with covariates of baseline ACQ-5, region, baseline maintenance OCS therapy, exacerbations in the year prior to the study, baseline percent predicted $\mathrm{FEV}_{1}$, treatment group and visit, plus interaction terms for visit by baseline and visit by treatment group.

\section{Results}

\section{Patient Population}

This post hoc analysis was conducted in the mITT population from the MENSA trial, which included 576 patients, of whom $385(66.8 \%)$ received mepolizumab and 191 (33.2\%) received placebo; 75 patients had previously received omalizumab. A total of 272 patients were nonatopic (class 0), 181 were atopic (class 1, 2 and 3) and 94 were strongly atopic (class 4, 5 and 6); atopy data were missing for 29 patients. Blood eosinophil count data were missing for an additional seven patients. Of the 576 patients in the overall population, $202(35 \%)$ patients were HDM-sensitive and 345 (60\%) were not; HDM sensitivity data were missing for 29 patients. Baseline demographics and disease characteristics by atopy status are shown in Table 1. In the groups categorized as strongly atopic (classes 4, 5 and 6), atopic (classes 1,2 and 3) and non-atopic (class 0 ) the mean number of exacerbations in the year prior to the study was similar (3.7, 3.5 and 3.8, respectively) and geometric mean baseline blood eosinophil counts were also similar $(280,310$ and 300 cells $/ \mu \mathrm{L}$, respectively) (Table 1).

\section{Clinically Significant Exacerbations}

Compared with placebo, mepolizumab treatment resulted in reductions in the annual rate of clinically significant exacerbations in all atopy subgroups where an analysis could be performed (ie, baseline blood eosinophil count within atopy subgroups), with the exception of non-atopic patients with baseline blood eosinophil counts of $<150$ cells $/ \mu \mathrm{L}$ where the rate was numerically higher with mepolizumab (Figure 1). Comparing across atopy subgroups in patients with baseline blood eosinophil counts $\geq 300$ cells $/ \mu \mathrm{L}$, reductions in clinically significant exacerbations were numerically higher in the non-atopic subgroup (74\%) compared with the atopic (43\%) and strongly atopic (25\%) subgroups (Figure 1). Reductions were similar in non-atopic and atopic patients with blood eosinophil counts $\geq 150-300$ cells $/ \mu \mathrm{L}$. In the placebo group, annual exacerbation rates increased with increasing baseline blood eosinophil count in the nonatopic subgroups, while there was no obvious trend in patients who were atopic or strongly atopic.

In addition, mepolizumab versus placebo numerically reduced the annual rate of clinically significant exacerbations consistently across all HDM sensitivity subgroups where an analysis could be performed (Figure 2). Within these subgroups, annual exacerbation rates were similar for patients 
Table I Patient Baseline Demographics and Clinical Characteristics

\begin{tabular}{|c|c|c|c|}
\hline & $\begin{array}{l}\text { Non-Atopic } \\
(\mathbf{N}=\mathbf{2 7 2})\end{array}$ & $\begin{array}{l}\text { Atopic } \\
(\mathrm{N}=\mid \mathbf{8 I})\end{array}$ & $\begin{array}{l}\text { Strongly Atopic } \\
(\mathrm{N}=94)\end{array}$ \\
\hline Age, years, mean $(S D)$ & $54(13)$ & $50(14)$ & $38(15)$ \\
\hline Gender, female, n (\%) & $156(57)$ & $99(55)$ & $56(60)$ \\
\hline Body mass index, $\mathrm{kg} / \mathrm{m}^{2}$, mean (SD) & $27.9(5.6)$ & $28.3(6.2)$ & $26.6(5.9)$ \\
\hline Duration of asthma, years, mean (SD) & $18(13)$ & $21(14)$ & $23(13)$ \\
\hline Proportion of patients on long-term OCS, n (\%) & $75(28)$ & $44(24)$ & $6(6)$ \\
\hline Baseline OCS daily does, mg, mean (SD) & II.4 (8.8) & I4.I (II.7) & $9.3(1.8)$ \\
\hline Proportion of patients who received omalizumab & $30(11)$ & $33(18)$ & $10(11)$ \\
\hline Number of exacerbations in 12 months prior to screening, mean (SD) & $3.8(2.6)$ & $3.5(2.5)$ & $3.7(2.9)$ \\
\hline Pre-bronchodilator percent predicted $\mathrm{FEV}_{1}$, mean (SD) & $60(18)$ & $62(19)$ & $63(17)$ \\
\hline Baseline blood eosinophil counts, cells/ $\mu \mathrm{L}$, geometric mean (SD logs) & $300(1.04)$ & $310(0.97)$ & $280(0.83)$ \\
\hline Baseline total IgE level, U/mL, geometric mean (SD logs) & $85(1.38)$ & $201(1.30)$ & $608(1.16)$ \\
\hline \multicolumn{4}{|l|}{ Sensitivity to different allergens, $\mathrm{n}(\%)$} \\
\hline $\mathrm{HDMs}^{\mathrm{a}}$ & - & $119(66)$ & $83(88)$ \\
\hline Dog dander & - & $72(40)$ & $69(73)$ \\
\hline Cat dander & - & $65(36)$ & $7 \mid(76)$ \\
\hline A. alternata & - & $29(16)$ & $24(26)$ \\
\hline Cockroach & - & $44(24)$ & $36(38)$ \\
\hline
\end{tabular}

Notes: ${ }^{a} D$. pteronyssinus/D. farinae combined.

Abbreviations: FEV , forced expiratory volume in I second; HDM, house dust mite; IgE, immunoglobulin E; OCS, oral corticosteroid; SD, standard deviation.

sensitive to HDMs (1.71 event/year) versus those not sensitive to HDMs (1.66 event/year) in the placebo group.

\section{Asthma Control}

Overall, ACQ-5 scores were consistently numerically improved with mepolizumab versus placebo in patients with blood eosinophil counts $\geq 300$ cells $/ \mu \mathrm{L}$ compared with lower counts, with treatment differences numerically similar irrespective of atopic status (Figure 3). In patients with a baseline blood eosinophil count $<150$ and $\geq 150-300$ cells $/ \mu \mathrm{L}$, numerical improvements in ACQ-5 score with mepolizumab versus placebo were only observed in non-atopic but not in atopic or strongly atopic subgroups (Figure 3). ACQ-5 score was also consistently numerically improved with mepolizumab versus placebo irrespective of sensitivity to HDMs and other allergens. Patients sensitive to HDM including those sensitive to $\geq 1$ and $\geq 2$ additional allergens demonstrated numerically smaller reductions in ACQ-5 score compared with patients not sensitive to HDM (Figure 4).

\section{Discussion}

In this post hoc subgroup analysis of the MENSA study, mepolizumab reduced the rate of clinically significant exacerbations in patients with asthma and a baseline blood eosinophil count $\geq 150$ cells $/ \mu \mathrm{L}$, regardless of atopic status and strength, and in HDM-sensitive and nonsensitive patients. Improvements in asthma control were also shown with mepolizumab versus placebo in all patients with baseline blood eosinophil counts $\geq 300$ cells $/ \mu \mathrm{L}$ and in non-atopic patients with baseline blood eosinophil counts of $<300$ cells $/ \mu \mathrm{L}$, as well as in HDMsensitive and non-sensitive patients. These results demonstrate the efficacy of mepolizumab across a range of eosinophil thresholds, irrespective of atopic status, and highlight that among patients with severe eosinophilic asthma, clinically important benefits with mepolizumab treatment may be achieved across a broad range of atopic phenotypes. These findings are also consistent with a recent real-world study, which demonstrated that mepolizumab improved exacerbation frequency, OCS use, symptom control and lung function for patients with severe eosinophilic asthma, irrespective of allergic status. $^{14}$

Patients with severe asthma often have comorbidities, which increase disease burden and the risk of exacerbations. ${ }^{15}$ Exacerbations in turn have a substantial impact on health-related quality of life for patients with severe asthma, and are associated with considerable healthcare costs. ${ }^{16-18}$ Therefore, it is important to select an appropriate add-on therapy to help reduce exacerbations and 


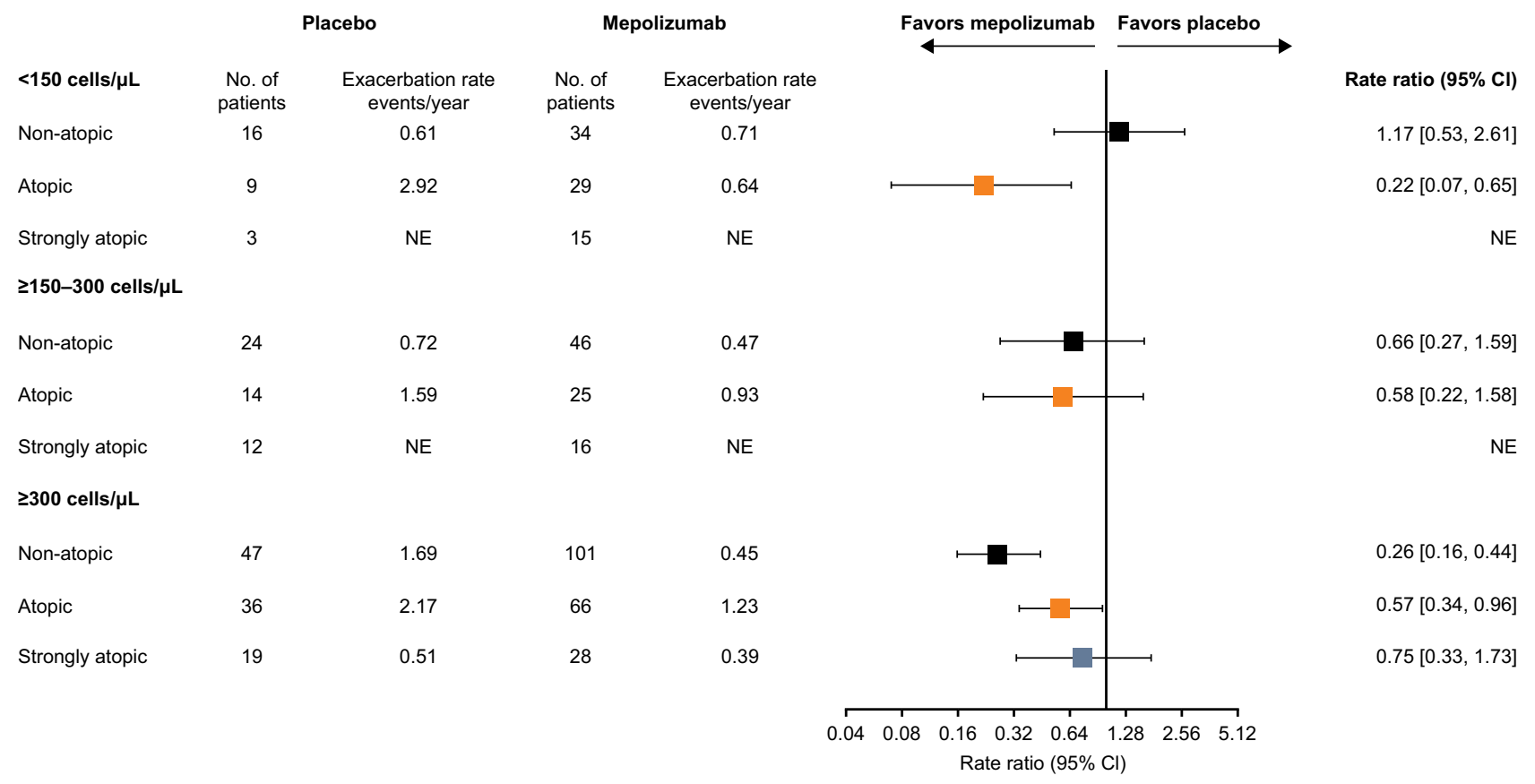

Figure I Rate ratios for clinically significant exacerbations by atopy/baseline blood eosinophil count status. Atopy was defined according to sensitization to any one of the following allergens: A. alternata, cockroach, HDM, cat dander and dog dander. Non-atopic: class 0 (IgE <0.35 kU/L); atopic: classes I, 2 and 3 (IgE $\geq 0.35-17.5 \mathrm{kU} / \mathrm{L}$ ); strongly atopic: classes 4, 5 and 6 ( $\operatorname{lgE}>17.5 \mathrm{kU} / \mathrm{L})$.

Abbreviations: $\mathrm{Cl}$, confidence interval; HDM, house dust mite; lgE, immunoglobulin $\mathrm{E}$; NE, rate ratio could not be estimated due to insufficient patient numbers.

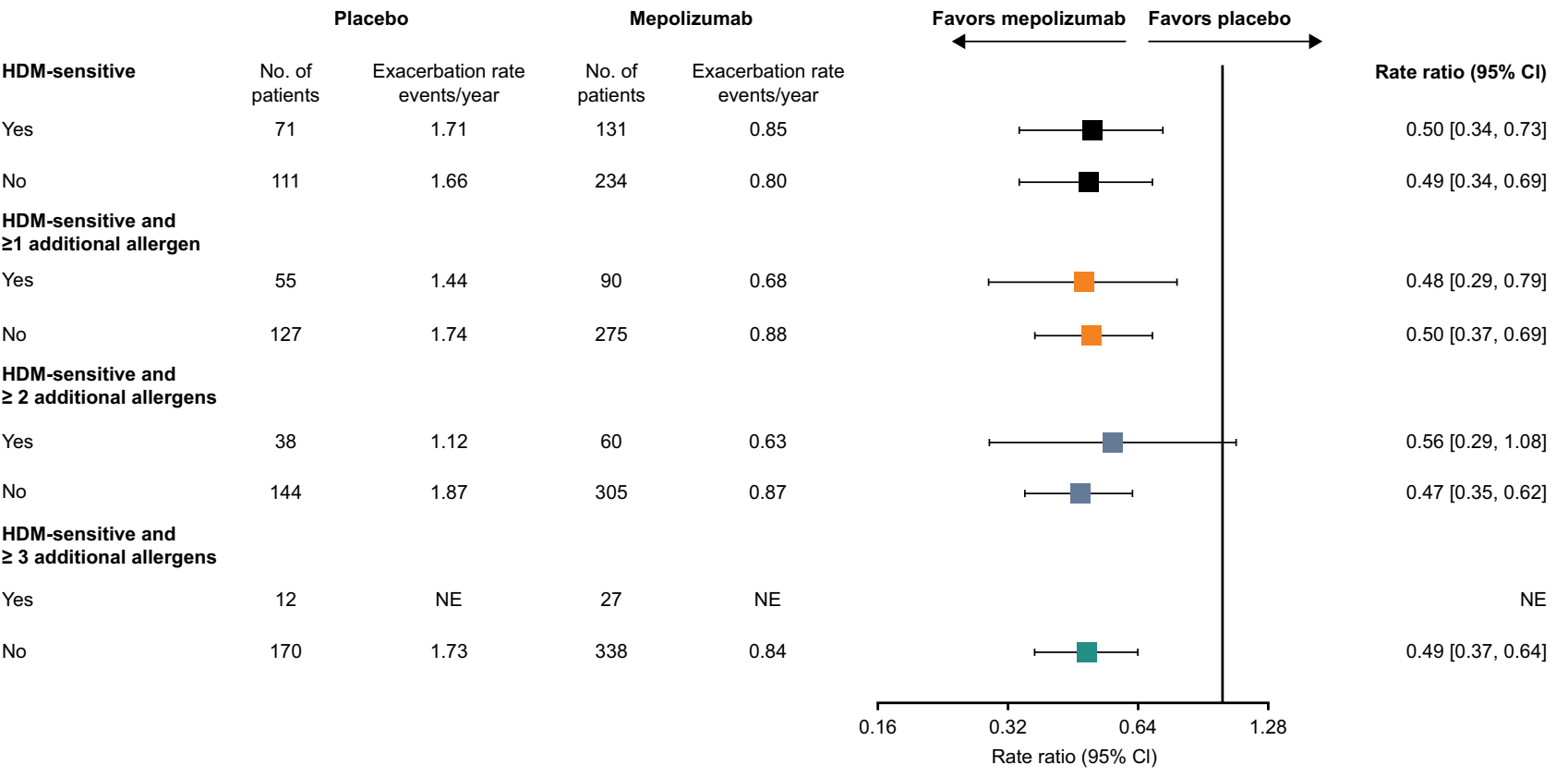

Figure 2 Rate ratios for clinically significant exacerbations by HDM sensitivity. HDM-sensitive (classes I-6: IgE $\geq 0.35 \mathrm{kU} / \mathrm{L}$ to $D$. farinae and/or $D$. pteronyssinus) or HDM non-sensitive (class $0: \operatorname{lgE}<0.35 \mathrm{kU} / \mathrm{L}$ to $D$. farinae and/or $D$. pteronyssinus). Within these categories, patients were grouped according to sensitivity to other allergens (A. alternata, cockroach, cat dander or dog dander; classes $\mathrm{I}-6$ : $\geq 0.35 \mathrm{kU} / \mathrm{L}$ ) to $\geq \mathrm{I}, \geq 2$ or $\geq 3$ additional allergens.

Abbreviations: $\mathrm{Cl}$, confidence interval; HDM, house dust mite; lgE, immunoglobulin $\mathrm{E}$; NE, rate ratio could not be estimated due to insufficient patient numbers.

improve asthma control. We observed that mepolizumab versus placebo provided reductions in clinically significant exacerbations in non-atopic, atopic and strongly atopic patients. Additionally, in non-atopic individuals, a trend towards greater reductions with mepolizumab over placebo in clinically significant exacerbation rates with increasing blood eosinophil count was observed. As such, mepolizumab may be an important treatment option for patients who 


\begin{tabular}{|c|c|c|c|c|c|c|c|}
\hline \multirow[b]{2}{*}{$<150$ cells/ $\mu \mathrm{L}$} & \multicolumn{2}{|c|}{ Placebo } & \multicolumn{2}{|c|}{ Mepolizumab } & \multirow[t]{2}{*}{ Favors mepolizumab } & \multicolumn{2}{|l|}{ Favors placebo } \\
\hline & $\begin{array}{l}\text { No. of } \\
\text { patients }\end{array}$ & $\begin{array}{l}\text { LS mean change } \\
\text { from baseline }\end{array}$ & $\begin{array}{l}\text { No. of } \\
\text { patients }\end{array}$ & $\begin{array}{l}\text { LS mean change } \\
\text { from baseline }\end{array}$ & & & $\begin{array}{r}\text { Treatment difference } \\
(95 \% \mathrm{Cl})\end{array}$ \\
\hline Non-atopic & 14 & -0.46 & 27 & -0.77 & 1 & & $-0.31[-1.00,0.38]$ \\
\hline Atopic & 7 & -0.60 & 25 & -0.43 & $\longrightarrow$ & & $0.17[-0.61,0.95]$ \\
\hline Strongly atopic & 3 & $\mathrm{NE}$ & 13 & $\mathrm{NE}$ & & & NE \\
\hline \multicolumn{8}{|c|}{$\geq 150-300$ cells $/ \mu \mathrm{L}$} \\
\hline Non-atopic & 20 & -0.63 & 44 & -0.86 & $\longmapsto$ & & $-0.22[-0.71,0.27]$ \\
\hline Atopic & 13 & -1.19 & 20 & -0.85 & $\longmapsto$ & & $0.35[-0.45,1.14]$ \\
\hline Strongly atopic & 12 & -0.58 & 14 & -0.61 & - & & $-0.03[-0.57,0.51]$ \\
\hline \multicolumn{8}{|l|}{$\geq 300$ cells $/ \mu \mathrm{L}$} \\
\hline Non-atopic & 46 & -0.40 & 90 & -1.15 & ra & & $-0.75[-1.06,-0.43]$ \\
\hline Atopic & 30 & -0.26 & 61 & -1.00 & $\mapsto-$ & & $-0.73[-1.19,0.28]$ \\
\hline \multirow[t]{3}{*}{ Strongly atopic } & 15 & -0.43 & 22 & -1.21 & $\longmapsto$ & & $-0.78[-1.30,-0.26]$ \\
\hline & & & & & -1.00 & 3.00 & \\
\hline & & & & Tre & lifference, mepolizumab & - placebo $(95 \% \mathrm{Cl})$ & \\
\hline
\end{tabular}

Figure 3 Change from baseline in ACQ- 5 score at Week 32 by atopy and baseline blood eosinophil count categories. Atopy was defined according to sensitization to any one of the following allergens: A. alternata, cockroach, HDM, cat dander and dog dander. Non-atopic: class 0 (IgE <0.35 kU/L; atopic: classes I, 2 and 3 (IgE $0.35-17.5$ kU/L); strongly atopic: classes 4,5 and 6 (lgE $17.6->100 \mathrm{kU} / \mathrm{L})$.

Abbreviations: ACQ, asthma control questionnaire; $\mathrm{Cl}$, confidence interval; HDM, house dust mite; IgE, immunoglobulin E; LS, least squares; NE, rate ratio could not be estimated due to insufficient patient numbers.

\begin{tabular}{|c|c|c|c|c|c|c|c|}
\hline \multirow[b]{2}{*}{ HDM-sensitive } & \multicolumn{2}{|c|}{ Placebo } & \multicolumn{2}{|c|}{ Mepolizumab } & Favors mepolizumab & \multicolumn{2}{|l|}{ Favors placebo } \\
\hline & $\begin{array}{c}\text { No. of } \\
\text { patients }\end{array}$ & $\begin{array}{l}\text { LS mean change } \\
\text { from baseline }\end{array}$ & $\begin{array}{l}\text { No. of } \\
\text { patients }\end{array}$ & $\begin{array}{l}\text { LS mean change } \\
\text { from baseline }\end{array}$ & 1 & & $\begin{array}{r}\text { Treatment difference } \\
(95 \% \mathrm{Cl})\end{array}$ \\
\hline Yes & 62 & -0.49 & 111 & -0.80 & & & $-0.31[-0.60,-0.02]$ \\
\hline No & 100 & -0.48 & 209 & -0.98 & $\mapsto$ & & $-0.50[-0.72,-0.29]$ \\
\hline \multicolumn{8}{|c|}{$\begin{array}{l}\text { HDM-sensitive and } \\
\geq 1 \text { additional allergen }\end{array}$} \\
\hline Yes & 48 & -0.56 & 79 & -0.83 & -1 & & $-0.28[-0.61,0.06]$ \\
\hline No & 114 & -0.46 & 241 & -0.95 & $\vdash$ & & $-0.49[-0.69,-0.29]$ \\
\hline \multicolumn{8}{|c|}{$\begin{array}{l}\text { HDM-sensitive and } \\
\geq 2 \text { additional allergens }\end{array}$} \\
\hline Yes & 32 & -0.61 & 53 & -0.86 & $\longmapsto-1$ & & $-0.25[0.68,0.17]$ \\
\hline No & 130 & -0.45 & 267 & -0.94 & $r$ & & $-0.49[-0.67,-0.30]$ \\
\hline Yes & 9 & -0.35 & 24 & -0.81 & $\longrightarrow$ & & $-0.46[-1.28,0.36]$ \\
\hline \multirow[t]{3}{*}{ No } & 153 & -0.48 & 296 & -0.94 & $\mapsto r$ & & $-0.46[-0.64,-0.29]$ \\
\hline & & & & -2.00 & -1.00 & 1.00 & \\
\hline & & & \multicolumn{5}{|c|}{ Treatment difference, mepolizumab - placebo $(95 \% \mathrm{Cl})$} \\
\hline
\end{tabular}

Figure 4 Change from baseline in ACQ-5 score at Week 32 by HDM sensitivity. HDM-sensitive (classes I-6: IgE $\geq 0.35 \mathrm{kU} / \mathrm{L}$ to $D$. farinae and/or D. pteronyssinus) or HDM non-sensitive (class $0: \lg E<0.35 \mathrm{kU} / \mathrm{L}$ to $D$. farinae and/or $D$. pteronyssinus). Within these categories, patients were grouped according to HDM sensitivity (classes $\mathrm{I}-6$ : $\geq 0.35$ $\mathrm{kU} / \mathrm{L}$ ) and to additional allergens (ie $\geq \mathrm{I}, \geq 2$ or $\geq 3$ additional allergens; A. alternata, cockroach, cat dander or dog dander).

Abbreviations: $\mathrm{ACQ}$, asthma control questionnaire; $\mathrm{Cl}$, confidence interval; HDM, house dust mite; lgE, immunoglobulin $\mathrm{E}$; LS, least squares.

remain uncontrolled on other biologics, including omalizumab. Indeed, a recent study found that in patients with severe eosinophilic asthma and an overlapping allergic phenotype who were uncontrolled with omalizumab therapy, switching from omalizumab to mepolizumab was associated with clinically significant improvements in asthma control, health 
status and exacerbation rate, with no new safety issues reported. $^{19}$

We did not observe any impact of mepolizumab on clinically significant exacerbations in non-atopic patients with baseline blood eosinophil counts of $<150$ cells $/ \mu \mathrm{L}$, although there was some improvement in asthma control (as shown by the improvement in ACQ-5 score) with mepolizumab versus placebo in this subset of patients. In addition, although the largest improvement in clinically significant exacerbations with mepolizumab versus placebo was seen in the atopic subgroup with baseline blood eosinophil counts $<150$ cells $/ \mu \mathrm{L}$, this is likely due to the relatively high exacerbation rate observed in the patients receiving placebo and the low number of patients in the placebo group $(\mathrm{N}=9)$. Therefore, overall our data provide further support for the use of 150 cells $/ \mu \mathrm{L}$ as a threshold for mepolizumab treatment in patients with severe asthma. ${ }^{20,21}$

We noted that the largest improvements in clinically significant exacerbation rates with mepolizumab versus placebo in patients with baseline blood eosinophil counts $\geq 300$ cells $/ \mu \mathrm{L}$, were in patients who were non-atopic compared with atopic and strongly atopic. This may indicate that eosinophils are a primary contributing factor to exacerbations in atopic patients with blood eosinophil counts $\geq 300$ cells $/ \mu \mathrm{L}$, and that other non-IL-5 related mechanisms may be contributing factors to exacerbation etiology at lower blood eosinophil counts. ${ }^{22}$ Similarly, patients sensitive to HDM including those sensitive to $\geq 1$ and $\geq 2$ additional allergens demonstrated numerically smaller reductions in ACQ-5 score compared with patients not sensitive to HDM, which may also suggest that atopy is a more important driver of symptoms in HDM-sensitive patients. However, further work will be needed to verify these findings, particularly because these trends were not consistently observed across subgroups or endpoints.

The presence of both IgE and eosinophilia are indicative of an asthma phenotype driven by type 2 inflammation, which in turn may be triggered by a number of stimuli, including IgE-mediated sensitivity to various allergens. ${ }^{23}$ The allergens selected for atopy assessments in the current study were chosen based on their effects on patients with asthma owing to their perennial nature, and their use in other published studies. ${ }^{24}$ We also felt it was important to determine the effect of HDM allergy on mepolizumab efficacy, given its widespread impact on patients with allergic disease and the association of specific allergen immunotherapy for HDM allergy with improvement in asthma outcomes. ${ }^{25,26}$ Therefore, the
HDM species, D. pteronyssinus and D. farinae, were selected for this study based on their global prevalence, perennial nature and frequent assessment in a clinical setting. ${ }^{25,27}$ Both species have also been shown to have substantial allergenic homology. ${ }^{28}$ Importantly, both reductions in clinically significant exacerbations and improvements in ACQ-5 score were consistent across HDM-sensitive and non-sensitive subgroups, independent of sensitivity to the additional allergens tested. These results confirm that selection of mepolizumab as an add-on treatment for patients with severe eosinophilic asthma is associated with a reduction in exacerbation rates and improved asthma symptom control, regardless of sensitivity to the common HDM allergen.

This analysis has several limitations which require consideration. First, the post hoc nature of the analysis and the fact that the number of patients was low in some of the subgroups should be kept in mind when interpreting the findings. Second, we did not account for seasonal variation in the frequency of exacerbations or assess the polysensitization status of patients to seasonal allergens. Although many patients with severe asthma experience frequent exacerbations throughout the year, some experience stable periods punctuated by significant exacerbations at particular times of the year. ${ }^{29}$ Third, it should be noted that atopy was measured using blood biochemistry only, the results of which may have been discordant with the clinical characteristics displayed by patients. Indeed, it has been suggested that reporting of asthma worsening in a clinical setting is a better predictor of response to omalizumab than IgE levels. ${ }^{30,31}$ Finally, as in previous post hoc analyses, we combined different doses and routes of administration of mepolizumab in this post hoc analysis, based on the similar reductions in exacerbation rate with the bioequivalent IV and SC doses shown in the original study. ${ }^{13}$

\section{Conclusions}

Reductions in clinically significant exacerbations and improvements in asthma control with mepolizumab versus placebo were generally consistent across the atopic subgroups in which an analysis could be performed. This suggests that mepolizumab is suitable for use in patients with severe asthma and an eosinophilic phenotype, irrespective of atopic status and HDM sensitivity. As such, these results provide valuable information for clinicians treating patients with severe asthma across a range of phenotypes. 


\section{Abbreviations}

ACQ, Asthma Control Questionnaire; CI, confidence interval; $\mathrm{FEV}_{1}$, forced expiratory volume in 1 second; FeNO, fractional exhaled nitric oxide; HDM, house dust mite; ICS, inhaled corticosteroid; IgE, immunoglobulin E; IL, interleukin; IV, intravenously; LS, least squares; mITT, modified intent-to-treat population; NE, rate ratio could not be estimated due to insufficient patient numbers; OCS, oral corticosteroid; SC, subcutaneously.

\section{Data Sharing Statement}

Anonymized individual participant data and study documents for the parent study can be requested for further research from www.clinicalstudydatarequest.com.

\section{Ethics Approval and Informed Consent}

This was a post hoc analysis of anonymized patient data from study MEA115588/NCT01691521. The primary study was conducted in accordance with the Declaration of Helsinki, the International Council on Harmonization Good Clinical Practice guideline, and the applicable country-specific regulatory requirements. The local institutional review board or ethics committee at each study center oversaw trial conduct and documentation. All patients provided written informed consent.

\section{Acknowledgments}

This secondary analysis and the primary study (MEA115588/NCT01691521) were funded by GlaxoSmithKline (GSK). Editorial support (in the form of writing assistance, including preparation of the draft manuscript under the direction and guidance of the authors, collating and incorporating authors' comments for each draft, assembling tables and figures, grammatical editing and referencing) was provided by Elizabeth Hutchinson, $\mathrm{PhD}, \mathrm{CMPP}$ and Laura Gardner, $\mathrm{PhD}$, CMPP, at Fishawack Indicia Ltd, part of Fishawack Health, UK, and was funded by GSK.

\section{Author Contributions}

All authors made a significant contribution to the work reported, whether that is in the conception, study design, execution, acquisition of data, analysis and interpretation, or in all these areas; took part in drafting, revising or critically reviewing the article; gave final approval of the version to be published; have agreed on the journal to which the article has been submitted; and agree to be accountable for all aspects of the work.

\section{Funding}

This post hoc, secondary subgroup analysis and the primary study (MEA115588/NCT01691521) were funded by GSK.

\section{Disclosure}

CMP, SM and SWY are all employees and shareholders of GSK. FCA is a former employee of GSK, holds GSK stocks/shares and is currently employed by Avillion US, Inc. MI has received fees from Actelion, AstraZeneca, Bayer, Berlin Chemie, Boehringer Ingelheim, Chiesi, CSL-Behring, Grifols, GSK, MSD, Novartis and Teva. JAD has received personal fees from AstraZeneca, GSK, Novartis and Sanofi-Aventis, has been an investigator for AstraZeneca, GSK, Novartis, Sanofi-Aventis, Grifols, BioCryst, CSL Ltd and Equilium, and holds shares in CSL Ltd. AB has received fees from GSK, Regeneron, Chiesi, AstraZeneca, Teva, Novartis and Boehringer Ingelheim and been an investigator for Novartis and AstraZeneca. The authors report no other conflicts of interest in this work.

\section{References}

1. Global Initiative for Asthma. Available from: Global Strategy for Asthma Management and Prevention. https://ginasthma.org/wpcontent/uploads/2020/06/GINA-2020-report_20_06_04-1-wms.pdf. Accessed January 2, 2020.

2. Wenzel S. Severe asthma: from characteristics to phenotypes to endotypes. Clin Exp Allergy. 2012;42(5):650-658. doi:10.1111/ j.1365-2222.2011.03929.x

3. Chung KF, Wenzel SE, Brozek JL, et al. International ERS/ATS guidelines on definition, evaluation and treatment of severe asthma. Eur Respir J. 2014;43(2):343-373. doi:10.1183/09031936.00202013

4. Tran TN, Zeiger RS, Peters SP, et al. Overlap of atopic, eosinophilic, and TH2-high asthma phenotypes in a general population with current asthma. Ann Allergy Asthma Immunol. 2016;116(1):37-42. doi:10.1016/j.anai.2015.10.027

5. Bonser LR, Erle DJ. The airway epithelium in asthma. Adv Immunol. 2019;142:1-34.

6. Genentech. Omalizumab (XOLAIR) US prescribing information. Available from: https://www.accessdata.fda.gov/drugsatfda_docs/ label/2018/103976s5231lbl.pdf. Accessed January 2, 2020.

7. Genentech. Omalizumab (XOLAIR) EU summary of product characteristics. Available from: https://www.ema.europa.eu/en/docu ments/product-information/xolair-epar-product-information_en.pdf. Accessed January 2, 2020.

8. GlaxoSmithKline. Mepolizumab (NUCALA) US prescribing information. Available from: https://www.gsksource.com/pharma/con tent/dam/GlaxoSmithKline/US/en/Prescribing_Information/Nucala/ pdf/NUCALA-PI-PIL-IFU-COMBINED.PDF. Accessed January 2, 2020. 
9. GlaxoSmithKline. Mepolizumab (NUCALA) EU summary of product characteristics. Available from: https://www.ema.europa.eu/en/ documents/product-information/nucala-epar-product-information_en. pdf. Accessed January 2, 2020.

10. Busse WW. Biological treatments for severe asthma: a major advance in asthma care. Allergol Int. 2019;68(2):158-166. doi:10.1016/j. alit.2019.01.004

11. Albers FC, Mullerova H, Gunsoy NB, et al. Biologic treatment eligibility for real-world patients with severe asthma: the IDEAL study. $J$ Asthma. 2018;55(2):152-160. doi:10.1080/ 02770903.2017.1322611

12. Tabatabaian F, Ledford DK. Omalizumab for severe asthma: toward personalized treatment based on biomarker profile and clinical history. J Asthma Allergy. 2018;11:53-61. doi:10.2147/JAA.S107982

13. Ortega HG, Liu MC, Pavord ID, et al. Mepolizumab treatment in patients with severe eosinophilic asthma. $N$ Engl J Med. 2014;371 (13):1198-1207. doi:10.1056/NEJMoa1403290

14. Pelaia C, Crimi C, Pelaia G, et al. Real-life evaluation of mepolizumab efficacy in patients with severe eosinophilic asthma, according to atopic trait and allergic phenotype. Clin Exp Allergy. 2020;50 (7):780-788. doi:10.1111/cea.13613

15. Brinke A, Sterk PJ, Masclee AA, et al. Risk factors of frequent exacerbations in difficult-to-treat asthma. Eur Respir J. 2005;26 (5):812-818. doi:10.1183/09031936.05.00037905

16. O'Neill S, Sweeney J, Patterson CC, et al. The cost of treating severe refractory asthma in the UK: an economic analysis from the British Thoracic Society Difficult Asthma Registry. Thorax. 2015;70 (4):376-378. doi:10.1136/thoraxjnl-2013-204114

17. Zeiger RS, Schatz M, Dalal AA, et al. Utilization and costs of severe uncontrolled asthma in a managed-care setting. $J$ Allergy Clin Immunol Pract. 2016;4(1):120-129. doi:10.1016/j.jaip.2015.08.003

18. Mullerova H, Cockle SM, Gunsoy NB, Nelsen LM, Albers FC. Clinical characteristics and burden of illness among adolescent and adult patients with severe asthma by asthma control: the IDEAL Study. J Asthma. 2019;1-16.

19. Chapman KR, Albers FC, Chipps B, et al. The clinical benefit of mepolizumab replacing omalizumab in uncontrolled severe eosinophilic asthma. Allergy. 2019;74(9):1716-1726. doi:10.1111/all.13850

20. Yancey SW, Keene ON, Albers FC, et al. Biomarkers for severe eosinophilic asthma. $J$ Allergy Clin Immunol. 2017;140 (6):1509-1518. doi:10.1016/j.jaci.2017.10.005

21. Ortega HG, Yancey SW, Mayer B, et al. Severe eosinophilic asthma treated with mepolizumab stratified by baseline eosinophil thresholds: a secondary analysis of the DREAM and MENSA studies. Lancet Respir Med. 2016;4(7):549-556. doi:10.1016/S22132600(16)30031-5
22. Ramsahai JM, Hansbro PM, Wark PAB. Mechanisms and Management of Asthma Exacerbations. Am J Respir Crit Care Med. 2019;199(4):423-432. doi:10.1164/rccm.201810-1931CI

23. Fahy JV. Type 2 inflammation in asthma-present in most, absent in many. Nat Rev Immunol. 2015;15(1):57-65. doi:10.1038/nri3786

24. Arroyave WD, Rabito FA, Carlson JC. The relationship between a specific IgE level and asthma outcomes: results from the 2005-2006 National Health and Nutrition Examination Survey. $J$ Allergy Clin Immunol Pract. 2013;1(5):501-508. doi:10.1016/j. jaip.2013.06.013

25. Calderon MA, Linneberg A, Kleine-Tebbe J, et al. Respiratory allergy caused by house dust mites: what do we really know? $J$ Allergy Clin Immunol. 2015;136(1):38-48. doi:10.1016/j. jaci.2014.10.012

26. Virchow JC, Backer V, Kuna P, et al. Efficacy of a house dust mite sublingual allergen immunotherapy tablet in adults with allergic asthma: a randomized clinical trial. JAMA. 2016;315 (16):1715-1725. doi:10.1001/jama.2016.3964

27. Calderon MA, Casale TB, Nelson HS, Demoly P. An evidence-based analysis of house dust mite allergen immunotherapy: a call for more rigorous clinical studies. $J$ Allergy Clin Immunol. 2013;132 (6):1322-1336. doi:10.1016/j.jaci.2013.09.004

28. Shafique RH, Klimov PB, Inam M, Chaudhary FR, OConnor BM. Group 1 allergen genes in two species of house dust mites, Dermatophagoides farinae and D. pteronyssinus (Acari: pyroglyphidae): direct sequencing, characterization And polymorphism. PLoS One. 2014;9(12):e114636. doi:10.1371/journal.pone.0114636

29. Ortega H, Chupp G, Bardin P, et al. The role of mepolizumab in atopic and nonatopic severe asthma with persistent eosinophilia. Eur Respir J. 2014;44(1):239-241. doi:10.1183/09031936.00220413

30. Bousquet J, Rabe K, Humbert M, et al. Predicting and evaluating response to omalizumab in patients with severe allergic asthma. Respir Med. 2007;101(7):1483-1492. doi:10.1016/j. rmed.2007.01.011

31. Harris JM, Wong DA, Kapp AV. Development of the Asthma Control Composite outcome measure to predict omalizumab response. Ann Allergy Asthma Immunol. 2011;107(3):273-280. doi:10.1016/j. anai.2011.06.005

\section{Publish your work in this journal}

The Journal of Asthma and Allergy is an international, peer-reviewed open-access journal publishing original research, reports, editorials and commentaries on the following topics: Asthma; Pulmonary physiology; Asthma related clinical health; Clinical immunology and the immunological basis of disease; Pharmacological interventions and new therapies. The manuscript management system is completely online and includes a very quick and fair peer-review system, which is all easy to use. Visit http://www.dovepress.com/testimonials.php to read real quotes from published authors. 